\title{
Combined electroneurographic and electromyographic studies in lead workers
}

\author{
Jiann-Horng Yeh, Yang-Chyuan Chang, Jung-Der Wang
}

\begin{abstract}
Objectives-To evaluate the effects of chronic exposure to lead on the peripheral nervous system in lead workers.

Methods-Nerve conduction velocity and electromyographic studies were performed on 31 lead workers of a battery recycling factory and 31 sex and age matched controls. 25 cases with mild distal extensor weakness of the upper limbs were classified as the lead neuropathy subgroup and the rest of the lead workers as the lead exposure subgroup. Blood lead concentrations and haematological and biochemical data were recorded. An index of cumulative exposure to lead was calculated by the summation of multiplying the average blood concentration of lead with the duration of exposure at various jobs.
\end{abstract}

Results-Compared with the control group, the distal motor latency of the median nerve was significantly prolonged in the lead neuropathy subgroup, but not in the exposure subgroup. Only six of 31 workers had nerve conduction abnormalities, whereas electromyographic evidence of denervation was found in $\mathbf{9 3 . 5 \%}$ of the lead neuropathy subgroup and $83.5 \%$ in the lead exposure subgroup. The electromyographic abnormalities found were neurogenic polyphasic waves in all 29 workers with abnormal electromyographic findings (grade +++ in seven cases and grade ++ in the rest). Spontaneous activity was only recorded in seven workers, with grade + in four and grade ++ in three. There was a positive linear correlation between the index of cumulative exposure to lead and the distal motor latencies of the tibial nerve as well as a negative correlation with conduction velocities of the sural nerve after multivariate analysis and control of potential confounding by age and sex. No correlation could be found between the electrophysiological values and a simple duration of exposure or concentration of blood lead. A non-parametric analysis showed that there was a trend of higher index of cumulative exposure to lead with more severe electromyographic changes. Electromyographic abnormality also occurred in workers with blood lead concentrations between 17.4 and $58 \mu \mathrm{g} / \mathrm{dl}$. Conclusion-Electromyographic study in the distal extensors of the upper limbs may be used as a tool for biological monitoring of effect in lead workers.

(Occup Environ Med 1995;52:415-419)

Keywords: lead; neurotoxicity; electroneurography; electromyography

The peripheral nervous system is a major target organ in lead intoxication. An outbreak of severe neuropathy due to lead intoxication has been reported in Taiwan, ${ }^{1}$ but overt lead poisoning is now uncommon in developed countries due to an improvement in occupational hygiene and medical surveillance. The neurotoxic effects of long term increased lead absorption in asymptomatic lead workers has become a major concern in past decades. Measurement of nerve conduction velocities (NCVs) and electromyography (EMG) have been used for this purpose. However, results of the NCV studies were inconsistent among different investigators. Some authors found a significant slowing of $\mathrm{NCVs}^{2-15}$ whereas others were unable to show such changes. ${ }^{16-18}$ Such a variation is probably due to methodological differences in choice of nerves, examination techniques, and analytical methods. ${ }^{7}$ Baker et al proposed to abolish this inconsistency with a well designed prospective study and standardised techniques. Denervation changes found by EMG were reported to be probably important neurophysiologically in the absence of alteration of NCVs. Combined use of EMGs and NCVs to evaluate subclinical lead neuropathy has rarely been mentioned in the scientific literature. In our study, we applied a prospective electrophysiological study in 31 lead workers to determine the NCVs and EMGs in the lead workers and to assess the relation between these electrophysiological changes and concentrations of blood lead $(\mathrm{PbB})$ and index of cumulative exposure to lead (ICL).

Materials and methods

SUBJECTS

Thirty one lead workers (28 men and three women) from a battery recycling factory were included in this study. Their mean (range) age was 39.4 (24-62) years and the mean (range) duration of lead exposure was 30.4 (6-81) months. The ICL was calculated by 
multiplying the average concentrations of blood lead in various jobs with the duration of each job. The mean (range) ICL was 2018 (227-5214) month $\times \mu \mathrm{g} / \mathrm{dl}$. Thirty one age and sex matched non-exposed controls without any history or physical findings related to diabetes mellitus or chronic alcoholism were also enrolled to be the control group.

CLINICAL AND NEUROLOGICAL ASSESSMENT All the lead workers were given careful physical and neurological examinations so that any neurological conditions other than lead exposure could be recognised. Special attention was paid to muscle strength, especially that of the limb extensors. Only workers with no other neurological problems were selected for our study. We classified lead workers who had clinically obvious motor weakness as the lead neuropathy subgroup and other workers as the lead exposure subgroup.

\section{BIOCHEMICAL TESTS}

Blood lead was assessed by atomic absorption spectrophotometry. Haemoglobin concentration, packed cell volume, and renal function tests (blood urea nitrogen and blood creatinine) were determined by standard clinical laboratory methods. Anaemia was defined as a haemoglobin concentration below $12 \mathrm{~g} / \mathrm{dl}$ in the men and $10 \mathrm{~g} / \mathrm{dl}$ in the women. Azotaemia was recorded as serum urea nitrogen above 20 $\mathrm{mg} / \mathrm{dl}$ or serum creatinine above $1.5 \mathrm{mg} / \mathrm{dl}$.

\section{NEUROPHYSIOLOGICAL TESTS}

Studies of NCVs and EMGs were performed with a Medelec MS-20 two channel electromyograph in a warm laboratory $\left(24-26^{\circ} \mathrm{C}\right)$.

\section{Nerve conduction velocity study}

With conventional techniques, motor nerve conduction was studied on the median and the ulnar nerve (elbow to wrist) and the peroneal and the tibial nerve (knee to ankle). The absolute latency and the amplitude of the compound muscle action potential were measured and the motor conduction velocity was calculated. The median and the ulnar (wrist to finger) and the sural (midcalf to ankle) nerves were studied for antidromic sensory conduction. The amplitude and the absolute latency of the sensory action potential were measured for analysis. Nerve conduction values outside the absolute range of our laboratory norms were considered abnormal. Nerve conduction velocity, distal latency, and amplitude of the action potential were evaluated in all the sampled nerves.

\section{Electromyography study}

The concentric unipolar recording technique was used to obtain EMGs of the bilateral extensor indicis proprius and the first dorsal interossei muscles. Spontaneous activity during relaxation of the sampled muscles (including fibrillation potentials, positive waves, and fasciculation potentials) were carefully scored as + for one, ++ for two, +++ for three, and ++++ for four or more episodes of sponta-
Table 1 Prevalence of various symptoms and signs in 31 workers from a battery recycling factory

\begin{tabular}{|c|c|}
\hline & $\begin{array}{l}\text { Workers } \\
n(\%)\end{array}$ \\
\hline $\begin{array}{l}\text { Gastrointestinal system } \\
\text { (colic, diarrhoea, etc) }\end{array}$ & $4 / 31(13)$ \\
\hline General malaise & $4 / 31(13)$ \\
\hline Arthralgia & $8 / 31(26)$ \\
\hline Anaemia & $4 / 28(14)$ \\
\hline $\begin{array}{l}\text { Central nervous system } \\
\text { (headache, dizziness, etc) }\end{array}$ & $1 / 31(3)$ \\
\hline Peripheral nervous system: & $25 / 31(81)$ \\
\hline Weakness of wrist extensor & $25 / 25$ \\
\hline Weakness of foot dorsiflexion & $6 / 25$ \\
\hline Abnormalities of nerve conduction velocity & $6 / 31(19)$ \\
\hline Abnormalities of electromyography: & $29 / 31(94)$ \\
\hline Spontaneous activities & $7 / 29$ \\
\hline Polyphasic waves & $29 / 29$ \\
\hline
\end{tabular}

neous potentials in a recording period of $100 \mathrm{~ms}$. During minimal contraction of the sampled muscles, special attention was paid to the presence of polyphasic (more than five phases) motor unit potentials. Polyphasic motor unit potentials were scored in the same way as spontaneous potentials - for example, ++ for two polyphasic motor units within $100 \mathrm{~ms}$. A denervation abnormality of the EMG was defined as presence of any spontaneous potentials or grade ++ or more polyphasic motor unit potentials of wide duration and high amplitude. An abnormality of the EMG related to exposure to lead was defined as having denervation abnormalities of the EMG symmetrically in the bilateral extensor indicis proprius but normal EMG in the first dorsal interossei. The EMG study was not performed in the controls because of its invasive nature.

\section{STATISTICAL ANALYSIS}

Student's $t$ tests and rank sum test were performed to compare all variables of NCVs and EMGs between the workers and controls. Simple and multiple linear regression analyses were performed to determine the association between these electrophysiological variables and their predictors including age, sex, and ICL. A significant difference related to a $\mathrm{P}$ value $<0.05$

\section{Results}

CLINICAL AND NEUROLOGICAL FINDINGS AND BIOCHEMICAL TESTS

Table 1 summarises the prevalence of clinical manifestations related to lead intoxication. Although none of the workers complained of motor weakness in general or at work, we found that $80 \%$ of workers had extensor weakness of the distal upper limbs. Weakness in dorsiflexion of the foot occurred in six of these workers. Other gastrointestinal, haematological, and joint symptoms were rarely prevalent. The mean (range) $\mathrm{PbB}$ was 63 (17 to 186$) \mu \mathrm{g} / \mathrm{dl}$. Routine biochemical study of the blood including liver and renal function tests failed to show any significant abnormalities. Four workers were anaemic.

ELECTROPHYSIOLOGICAL TESTS

Tables 2 and 3 show the results of NCV studies in the lead workers and the matched 
Table 2 Comparison of motor nerve conduction studies (mean (SD)) between 31 lead workers from a battery recycling factory and 31 age sex matched controls

\begin{tabular}{|c|c|c|c|c|c|c|}
\hline & \multicolumn{2}{|c|}{ Distal latency (ms) } & \multicolumn{2}{|c|}{ Evoked amplitude $(\mathrm{mV})$} & \multicolumn{2}{|c|}{ Nerve conduction velocity $(\mathrm{m} / \mathrm{s})$} \\
\hline & Workers & Controls & Workers & Controls & Workers & Controls \\
\hline $\begin{array}{l}\text { Median nerve } \\
\text { Ulnar nerve } \\
\text { Peroneal nerve } \\
\text { Tibeal nerve }\end{array}$ & $\begin{array}{l}3.89(0.53)^{\star} \\
2.93(0.52) \\
4.55(0.86) \\
4.58(0.86)\end{array}$ & $\begin{array}{l}3.63(0.40) \\
2.97(0.36) \\
4.36(0.81) \\
4.86(1.27)\end{array}$ & $\begin{array}{r}9.3(2.4) \\
8.0(2 \cdot 1) \\
6.0(3.0) \\
11.9(5.5)\end{array}$ & $\begin{array}{r}8.7(2.6) \\
7.9(2.5) \\
6.6(2.0) \\
11.5(4.3)\end{array}$ & $\begin{array}{l}58 \cdot 6(5 \cdot 3) \\
57 \cdot 5(4 \cdot 6) \\
49 \cdot 6(4 \cdot 2) \\
48 \cdot 7(3 \cdot 4)\end{array}$ & $\begin{array}{l}58 \cdot 6(3 \cdot 7) \\
56 \cdot 4(5 \cdot 0) \\
49 \cdot 2(4 \cdot 4) \\
48 \cdot 9(4 \cdot 9)\end{array}$ \\
\hline
\end{tabular}

$\star \mathrm{P}<0 \cdot 05$.

Table 3 Comparison of sensory nerve conduction studies (mean (SD)) between 31 lead workers from a battery recycling factory and 31 age sex matched controls

\begin{tabular}{|c|c|c|c|c|c|c|}
\hline & \multicolumn{2}{|c|}{ Distal latency (ms) } & \multicolumn{2}{|c|}{ Evoked amplitude $(\mathrm{mV})$} & \multicolumn{2}{|c|}{ Nerve conduction velocity $(\mathrm{m} / \mathrm{s})$} \\
\hline & Workers & Controls & Workers & Controls & Workers & Controls \\
\hline $\begin{array}{l}\text { Median nerve } \\
\text { Ulnar nerve } \\
\text { Sural nerve }\end{array}$ & $\begin{array}{l}2.53(0.35) \\
2.36(0.39) \\
2.88(0.48)\end{array}$ & $\begin{array}{l}2.46(0.28) \\
2.23(0.25) \\
2.96(0.59)\end{array}$ & $\begin{array}{l}32.0(16.2) \\
26.9(16.7) \\
16.9(10.3)\end{array}$ & $\begin{array}{l}29 \cdot 8(16 \cdot 5) \\
24 \cdot 1(14 \cdot 3) \\
17 \cdot 7(9 \cdot 2)\end{array}$ & $\begin{array}{l}56 \cdot 8(7 \cdot 5) \\
54 \cdot 0(5 \cdot 7) \\
50 \cdot 1(5 \cdot 9)\end{array}$ & $\begin{array}{l}57 \cdot 2(5 \cdot 3) \\
53 \cdot 8(4 \cdot 5) \\
50 \cdot 1(5 \cdot 3)\end{array}$ \\
\hline
\end{tabular}

controls. The distal motor latencies of median nerves were significantly prolonged in the lead workers compared with the controls. The prevalence of abnormal EMGs was higher than that of NCVs (table $1,94 \% v 81 \%$ respectively). Table 1 shows that neurogenic polyphasic waves were found in all the workers with abnormal EMGs (grade +++ in seven cases and grade ++22 cases). Spontaneous activities were only recorded in seven workers (grade + in four and grade ++ in three). There was no significant difference in any of the electrophysiological variables between the two subgroups of lead workers. The prevalence of abnormal EMGs was high (83.3\%) in the lead exposure subgroup. The lowest PbB in a case of subclinical neuropathy, shown by electromyographic denervation, was $17 \cdot 4$ $\mu \mathrm{g} / \mathrm{dl}$. There was also no statistical difference in any electrophysiological variables between the workers with $\mathrm{PbB}$ above and below 60 $\mu \mathrm{g} / \mathrm{dl}$. Similarly, there were no significant differences between the workers who were exposed to lead for more and less than two years. The clinical neuropathy subgroup had a significantly higher ICL than the lead exposure subgroup. Likewise, the ICL of the workers with definitely abnormal NCVs was also higher than that of the workers with normal NCVs. Table 4 summarises the results of a multivariate multiple regression analysis to control two potential confounding factors: age and sex. We found a consistent positive association between the ICL and the distal motor latencies of tibial nerves as well as a significant negative association between the ICL and the

Table 4 Multiple regression analysis to show the significant influence on the elctrophysiological variables by index of cumulative exposure to lead

\begin{tabular}{llrll}
\hline $\begin{array}{l}\text { Dependent } \\
\text { variable }\end{array}$ & $\begin{array}{l}\text { Independent } \\
\text { variable }\end{array}$ & $\begin{array}{l}\text { Regression } \\
\text { coefficient (SEM) }\end{array}$ & $P$ value & $\begin{array}{l}\text { Model } \\
\text { fitting }\end{array}$ \\
\hline T-DML: & Intercept & $2.828(0.660)$ & 0.000 & $\mathrm{P}=0.005$ \\
& Age & $-0.003(0.012)$ & 0.815 & $R^{2}=0.375$ \\
& Sex & $1.171(0.374)$ & 0.004 & \\
S-SCV: & ICL & $0.000(0.000)$ & 0.003 & $\mathrm{P}=0.017$ \\
& Intercept & $53.641(5.148)$ & 0.000 & $R^{2}=0.309$ \\
& Age & $0.175(0.099)$ & 0.089 & \\
& Sex & $-5.855(2.916)$ & 0.055 & \\
& ICL & $-0.003(0.001)$ & 0.010 & \\
\hline
\end{tabular}

T-DML = tibial nerve distal motor latency; S-SCV = sural nerve sensory conduction velocity; ICL = index of cumulative lead exposure: a summation of exposure duration (month) $\times$ expected mean concentration of blood lead $(\mu \mathrm{g} / \mathrm{dl})$ at certain job.
NCVs of sural nerves after controlling for age and sex. No correlation could be found between the neurophysiological data and $\mathrm{PbB}$ or the duration of exposure to lead. With the non-parametric rank sum test we found a trend for higher ICL in those workers with more abnormal EMGs.

\section{Discussion}

Simpson et al in 1964 reported a lead worker with encephalopathy. ${ }^{19}$ The patient also had wasting of the intrinsic hand muscles, weakness of the shoulder girdle and neck muscles, and brisk tendon reflexes. His motor conduction velocity and distal motor latency of the ulnar nerves were normal, but there were signs of denervation on the EMG that were manifest as increased insertional activity, spontaneous fibrillation, reduced motor unit recruitment, and polyphasic units of long duration. Similar cases that presented with weakness, wasting, and fasciculation in the distal upper limbs but normal or nearly normal motor and sensory velocities with obvious evidence on an EMG of denervation were also documented as having clinically overt lead neuropathy in several previous reports. ${ }^{20-22}$ Beritic in 1989 declared that these electrophysiological findings were indistinguishable from those of motor neurone disease. ${ }^{21}$

In developed countries, occupational exposure to lead is almost adequately controlled and patients with overt lead neuropathy are relatively rare. ${ }^{22}$ Early detection of subclinical neuropathy in asymptomatic workers has therefore become a main focus in occupational medicine. It has been suggested that the study of NCVs might be useful in the early detection of lead poisoning. After a critical review and meta-analysis on NCVs in 32 studies on asymptomatic lead workers, Davis and Svendsgaard concluded that there were no substantive differences in NCV between the asymptomatic workers and normal controls. ${ }^{2}$ Because of wide ranges of the NCVs in the normal subjects and no consistent abnormalities in the NCVs of the lead workers, evaluation of NCVs seems impractical for early detection of lead neuropathy. 
In the reported nerve conduction studies on patients with lead neuropathy, not all the common neurographic variables-that is, NCV, distal latency, and evoked amplitudewere included in the analysis of the electrophysiological results. Moreover, nerves sampled were mainly in the upper limb. Slowing of the NCV was the only possible abnormal finding mentioned in these reports. We have studied motor and sensory nerves in the upper and lower limbs and analysed all the variables. Mean distal motor latency was mildly prolonged in workers with clinically overt lead neuropathy. The mean NCV did not differ from that in the normal controls, although five cases had abnormal NCVs. In the lead exposure subgroup of our study, there was no significant slowing of NCVs.

In 31 asymptomatic lead workers, Seppalainen and Hernberg found abundant abnormal EMGs that included fibrillation and diminished number of motor units. ${ }^{15}$ Signs of denervation on the EMG with increased polyphasic potentials were present in seven out of 20 cases in Buchthal and Behse's study ${ }^{6}$ and in four out of 38 cases in the study of Corsi's group. ${ }^{3}$ In an extensive review of neurophysiological studies in asymptomatic lead workers, Ehle reported that there was consistent evidence of denervation in the EMG study. ${ }^{23}$ As for the EMGs in our lead neuropathy subgroup, 24 out of 25 cases (96\%) had neurogenic polyphasic waves and $24 \%$ had spontaneous activities. Five out of these six workers in our lead exposure subgroup also showed signs of denervation on the EMGsneurogenic polyphasic waves with or without spontaneous activities. Of these two variables, spontaneous activity is a specific indicator of an active change in denervation and the neurogenic polyphasic wave is suggestive of a relatively chronic denervation process. As the disease progresses to the chronic state, the spontaneous activity will become less prominent and be replaced by polyphasic waves. ${ }^{24}$ So the polyphasic wave is the main variable on EMGs that can evaluate this chronic effect of lead neurotoxicity. Our neurophysiological findings were similar to those reported by Ehle $^{23}$ and Beritic. ${ }^{21}$ As we also could not show a significant difference in NCVs between the workers and the controls, it seems that the study of EMGs may be an alternative tool for the early detection of subclinical lead poisoning.

Jeyaratnam et al proposed that the distal segment of the peripheral nerves should show the earliest change. ${ }^{8} \mathrm{He}$ also suggested that the distal latency is a sensitive indicator of lead neuropathy. Our findings show that early conduction abnormalities in lead neuropathy are manifest by prolonged distal latencies rather than a slowing of NCVs. These changes in latency were less prominent than the abnormalities of the EMGs.

The disproportionately higher prevalence of evidence of denervation on the EMGs in contrast with the subtle changes in NCVs in lead workers strongly argues in favour of the "anterior horn cell" origin of neurotoxic action of lead. This is also documented in histopathological studies ${ }^{52122}$ and suggests that EMGs are good early indicators of the effect of lead on the nervous system. Thus EMGs may be used in future industrial monitoring of lead workers.

In our series, the neurophysiological findings did not show any significant association with $\mathrm{PbB}$ or the duration of exposure. A lack of positive correlation was also described in most other studies. ${ }^{2}$ Davis and Svendsgaard mentioned several factors contributory to the complex relation between $\mathrm{PbB}$ and variables of NCVs. ${ }^{2}$ First of all, $\mathrm{PbB}$ is a reliable indicator only for recent or current exposure and cannot be used to represent a chronic effect of exposure to lead. The selective loss of follow up in workers with high $\mathrm{PbBs}$ for various reasons and the interactive effects with antagonists such as zinc have also been mentioned as important influential factors. Nevertheless, the ICL in this paper may be an optimal estimate of chronic exposure to lead in the past. Because the ICL showed an association with the electrophysiological data after control of confounding by age and sex, we think that ICL may be a supplementary predictor for industrial monitoring of chronic neurotoxicity due to lead. As $90 \%$ of total body lead accumulates in the skeleton and the turnover time of skeletal lead is about 20 years, direct detection of concentrations of skeletal lead should be a good way to estimate the total body burden of lead. ${ }^{22} 25$ The $x$ ray fluorescence technique may serve as an acceptable indicator of the body burden of lead and a useful technique for lead screening purposes. As the technique involves a subject's exposure to radiation, calculation of ICL based on a careful field study in the working environment would be an alternative, although not so accurate for estimation of chronic exposure to lead.

There have been increased abnormal NCVs in lead workers who had $\mathrm{PbB}$ within the range of $30-70 \mu \mathrm{g} / \mathrm{dl}$ in the past. ${ }^{459122026}$ In our study, abnormal EMGs occurred in subclinical lead workers with $\mathrm{PbB}$ between 17.4 and $58 \mu \mathrm{g} / \mathrm{dl}$. As we have not found any clinical symptoms among lead workers who had already shown objective changes of muscle power on electrophysiological examination, we recommend that the industrial monitoring of the neurotoxicity of lead in workers should be more careful. Probably, the safe $\mathrm{PbB}$ for occupational exposure should be revised. ${ }^{27}$ Supplementary monitoring by EMGs may also be warranted to control this ancient industrial hazard.

1 Yip PK, Chang YC, Wang JD, Tsasi SY, Chen JS. A small outbreak of lead neuropathy in a tile factory. $f$ Formos Med Assoc 1988;87:60-5.

2 Davis JM, Svendsgaard DJ. Nerve conduction velocity and lead: a critical review and meta-analysis. In: Advances in neurobehavior toxicology: applications in environmental and occupational health. Chelsea, MI: Lewis, 1990:353-76.

3 Corsi G, Bartolucci GB, Fardin P, Negrin P, Manzoni S. Biochemical and electrophysiological study of subjects with a history of past lead exposure. Am 7 Ind Med 1984;6:281-90.

4 Bordo B, Massetto N, Musicco M, Filippini G, Boeri R Electrophysiologic changes in workers with "low" blood lead levels. Am ₹ Ind Med 1982;3:23-32. 
5 He F, Zhang S, Li G, Zhang S, Huang J, Wu Y. An electroneurographic assessment of subclinical lead neurotoxicity. Int Arch Occup Environ Health 1988;61: $141-6$

6 Buchthal F, Behse F. Electrophysiology and nerve biopsy in men exposed to lead. $B r f$ Ind Med 1979;36:135-47.

7 Ashby JAS. A neurological and biochemical study of early lead poisoning. $\mathrm{Br}$ f Ind $\mathrm{Med}$ 1980;37:133-40.

8 Jeyaratnam J, Devathasan G, Ong CN, Phoon WO, Wong PK. Neurological studies on workers exposed to lead. $\mathrm{Br}$ F Ind Med 1985;42:173-7.

9 Araki S, Yokoyama K, Aono H, Murata K. Psychological performance in relation to central and peripheral nerve performance in relation to central and peripheral nerve Am $\mathcal{\text { Ind }}$ Med 1986;9:535-42.

10 Baker EL, Feldman RG, White RA, Harley JP, Niles CA, Dinse GE, Berkey CS. Occupational lead neurotoxicity: a behavioural and electrophysiological evaluation. $\mathrm{Br} \mathcal{f}$ Ind Med 1984;41:352-61

11 Triebig G, Weltle D, Valentin H. Investigations on neurotoxicity of chemical substances at the workplace. Int Arch Occup Environ Health 1984;53:189-204.

12 Seppalainen AM, Tola S, Hernberg S, Kock B. Subclinical neuropathy at "safe" levels of lead exposure. Arch Environ Health 1975;30:180-3.

13 Feldman RG, Hayes MK, Younes R, Aldrich FD. Lead neuropathy in adults and children. Arch Neurol neuropathy in

14 Catton MJ, Harrison MJG, Fullerton PM, Kazantzis G. Subclinical neuropathy in lead workers. $B M F$ 1970;2: $80-2$.

15 Seppalainen AM, Hernberg S. Sensitive technique for detecting subclinical lead neuropathy. $B r \mathcal{F}$ Ind $M e d$ 1972;29:443-9.

16 Spivey GH, Baloh RW, Brown CP, Browdy BL, Campion DS, Valentine JL, et al. Subclinical effects of chronic increased lead absorption-a prospective study. III. neurologic findings at follow-up examination. $\mathcal{f}$ Occup Med 1980;22:607-12.

17 Baloh RW, Spivey GH, Brown CP, Morgan D, Campion DS, Browdy BL, et al. Subclinical effects of chronic increased lead absorption-a prospective study II. results of baseline neurologic testing. $\mathcal{F}$ Occup Med 1979; 21:490-6.

18 Nielsen CJ, Nielsen VK, Kirkby H, Gyntelberg F. Absence of peripheral neuropathy in long-term lead-exposed subjects. Acta Neurol Scand 1982;65:241-7.

19 Simpson JA, Seaton DA, Adams JF. Response to treatment with chelating agents of anemia, chronic encephalopathy, and myelopathy due to lead poisoning. I Neurol Neurosurg Psychiatry 1964;27:536-41.

20 Boothby JA, deJesus PV, Rowland LP. Reversible forms of motor neuron disease. Arch Neurol 1974;31:18-23.

21 Beritic T. Spinal origin of human lead neuropathy: this paper marks the 150 th anniversary of Paralysie de plomb ou saturnine by $\mathrm{L}$ Tanquerel des Planches. Am $\mathcal{F}$ Ind Med 1989;15:643-56.

22 Windebank AJ. Metal neuropathy. In: Peripheral neuropathy. Philadelphia: Saunders, 1992:1549-70.

23 Ehle AL. Lead neuropathy and electrophysiological studies in low level lead exposure: a critical review. Neurotoxicology 1986;7:203-16.

24 Aminoff MJ. Electrodiagnosis in clinical neurology, $3 r d$ ed. New York: Churchill Livingstone, 1992:261.

25 Wielopolski L, Ellis KJ, Vaswani AN. In vivo bone lead measurements: a rapid monitoring method for cumulameasurements: a rapid monitoring method for

26 Seppalainen AM. Neurophysiological approaches to the detection of early neurotoxicity in humans. CRC Crit Rev Toxicol 1988;18:245-98.

27 American Conference of Governmental Industrial Hygienists (ACGIH). 1993-1994 Threshold limit values for chemical substances and physical agents and biological exposure indices. Cincinnati, OH: ACGIH, 1993:57. 